International Journal of Distributed and Parallel Systems (IJDPS) Vol.3, No.4, July 2012

\title{
Space-Time Block Coding (STBC) for Wireless Networks
}

\author{
Santumon.S.D ${ }^{1}$ and B.R. Sujatha ${ }^{2}$ \\ ${ }^{1}$ Department of Electronics and Communication Engineering, MCE, Karnataka \\ santumon_sdeyahoo.com \\ ${ }^{2}$ Department of Electronics and Communication Engineering, MCE, Karnataka \\ brshsn61@gmail.com
}

\begin{abstract}
Wireless designers constantly seek to improve the spectrum efficiency/capacity, coverage of wireless networks and link reliability. Space-time wireless technology that uses multiple antennas along with appropriate signalling and receiver techniques offers a powerful tool for improving wireless performance. More advanced MIMO techniques are planned for future mobile networks in wireless Local Area Network (LANs) and Wide Area Network (WANs). Multiple antennas when used with appropriate Space-Time Coding (STC) techniques can achieve huge performance gains in multipath fading wireless links. The Space Time Coding has evolved as a most vibrant research area in wireless communications. Recently, Space-Time Block Coding (STBC) has been trying to incorporate in the forthcoming generation of mobile communication standard which aims to deliver true multimedia capability. This paper presents the Space-Time Block Codes (STBC) for wireless networks that uses multiple numbers of antennas at both transmitter and receiver. The simulations have been done in MATLAB. The STBC which includes the Alamouti Scheme as well as an orthogonal STBC for 4 transmit antenna case has been simulated and studied.
\end{abstract}

Keywords: Space-Time Coding (STC), Maximal Ratio Combining (MRC), Rayleigh fading, transmit diversity, smart antennas, Multiple Input Multiple Output (MIMO), QPSK, QAM.

\section{INTRODUCTION}

Wireless communication is, by any measure, the fastest growing segment of the communication industry. As such, it has captured the attention of the media and the imagination of the public. Cellular systems have experienced exponential growth over the last decade. Indeed, cellular phones have become a critical business tool and part of everyday life in most developed countries and are rapidly supplementing antiquated wireline systems in many developing countries. In addition, wireless local area networks currently supplement or replace wired networks in many homes, businesses and campuses. Many new applications, including wireless sensor networks, automated highways and factories, smart homes and appliances, and remote telemedicine, are emerging from research ideas to concrete systems. The explosive growth of wireless systems coupled with the proliferation of laptop and palmtop computers indicate a bright future for wireless networks, both as stand-alone systems and as part of the larger networking infrastructure. However, many technical challenges remain in designing robust wireless networks that deliver the performance necessary to support emerging applications.

In recent years, researchers have realized that many benefits as well as a substantial amount of performance gain of receive diversity can be reproduced by using multiple antennas at transmitter to achieve transmit diversity. In the early 1990's, development of transmit diversity techniques has started. Since then the interest in the topic has grown in a rapid fashion. In fact, we can expect multiple-input multiple-output (MIMO) technology [1] to be a 
International Journal of Distributed and Parallel Systems (IJDPS) Vol.3, No.4, July 2012

cornerstone of many wireless communication systems due to the potential increase in data rate and performance of wireless links offered by transmit diversity and MIMO technology.

\section{MIMO for Wireless Networks}

Digital communication using multiple-input-multiple output (MIMO), also called as "volume-to-volume" wireless link and has emerged as one of the most significant technical breakthroughs in modern communications. The technology figures prominently on the list of recent technical advances with a chance of resolving the bottleneck of traffic capacity in future Internet-intensive wireless networks. Perhaps even more surprising is that just a few years after its invention, the technology seems poised to penetrate large-scale standards-driven commercial wireless products and networks such as broadband wireless access systems, wireless local area networks (WLAN), third-generation (3G) networks and beyond.

MIMO systems can be defined as: Given an arbitrary wireless communication system, we consider a link in which the transmitting ends as well as the receiving end is equipped with multiple antenna elements as illustrated in Figure 1. The idea behind MIMO is that the signals on the transmit (TX) antennas at one end and the receive (RX) antennas at the other end are "combined" in such a way that the quality (bit-error rate or BER) or the data rate (bits/sec) of the communication for each MIMO user will be improved. Such an advantage can be used to increase both the network's quality of service and the operator's revenues significantly.

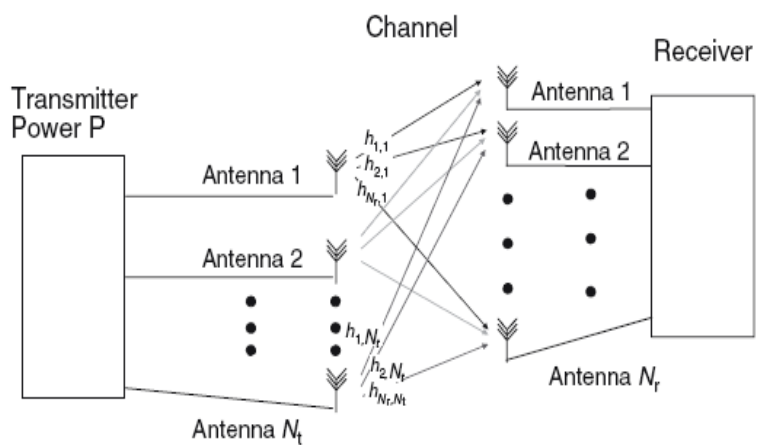

Figure 1: Multiple Input Multiple Output system.

A core idea in MIMO [1] systems are space-time signal processing in which time (the natural dimension of digital communication data) is complemented with the spatial dimension inherent in the use of multiple spatially distributed antennas. As such MIMO systems can be viewed as an extension of the so-called smart antennas, a popular technology using antenna arrays for improving wireless transmission dating back several decades.

It is important to note that each antenna element on a MIMO system operates on the same frequency and therefore does not require extra bandwidth. Also, for fair comparison, the total power through all antenna elements is less than or equal to that of a single antenna system. i.e.,

$$
\sum_{k=1}^{N} p_{\mathrm{k}} \leq \mathrm{P}
$$

where $\mathrm{N}$ is the total number of antenna elements, $\mathrm{p}_{\mathrm{k}}$ is the power allocated through the $\mathrm{k}^{\text {th }}$ antenna element, and $\mathrm{P}$ is the power if the system had a single antenna element. Effectively, the equation (1) ensures that a MIMO system consumes no extra power due to its multiple antenna elements. 
International Journal of Distributed and Parallel Systems (IJDPS) Vol.3, No.4, July 2012

\section{Space-Time Block Codes}

Space-time block codes (STBC) [2] are a generalized version of Alamouti scheme [3], but have the same key features. These codes are orthogonal and can achieve full transmit diversity specified by the number of transmit antennas. In other words, space-time block codes are a complex version of Alamouti's space-time code, where the encoding and decoding schemes are the same as there in the Alamouti space-time code on both the transmitter and receiver sides. The data are constructed as a matrix which has its columns equal to the number of the transmit antennas and its rows equal to the number of the time slots required to transmit the data. At the receiver side, the signals received are first combined and then sent to the maximum likelihood detector where the decision rules are applied.

Space-time block codes were designed to achieve the maximum diversity order for the given number of transmit and receive antennas subject to the constraint of having a simple linear decoding algorithm. This has made space-time block codes a very popular and most widely used scheme.

Training-based methods [4] seem to give very good results on the performance of channel estimation at the receiver. Pure training-based schemes can be considered as an advantage when an accurate and reliable MIMO channel needs to be obtained. However, this could also be a disadvantage when bandwidth efficiency is required. This is because pure training-based schemes reduce the bandwidth efficiency considerably due to the use of a long training sequence which is necessarily needed in order to obtain a reliable MIMO channel estimate. Because of the computation complexity of blind and semi-blind methods, many wireless communication systems still use pilot sequences to estimate the channel parameters at the receiver side.

\subsection{Alamouti Scheme}

Alamouti scheme is the basis of the Space Time Coding technique. The mathematical explanation of the scheme with two transmitting and one receiving antennas is also explained here. In this work, a two-branch transmit diversity scheme is implemented. Using two transmit antennas and one receive antenna, the scheme provides the same diversity order as maximalratio receiver combining (MRRC) [5] with one transmit antenna and two receive antennas. The scheme may easily be generalized to two transmit antennas and $\mathrm{M}$ receive antennas to provide a diversity order of $2 \mathrm{M}$.

At the transmitter side, a block of two symbols is taken from the source data and sent to the modulator. After that, Alamouti space-time encoder takes the two modulated symbols, in this case called $s_{1}$ and $s_{2}$ creates encoding matrix $S$ where the symbols $s_{1}$ and $s_{2}$ are mapped to two transmit antennas in two transmit time slots. The encoding matrix is given by:

$$
\mathrm{S}=\left(\begin{array}{ll}
\mathrm{s}_{1} & \mathrm{~s}_{2} \\
-\mathrm{s}_{2} * & \mathrm{~s}_{1} *
\end{array}\right)
$$

The fading coefficients denoted by $h_{1}(t)$ and $h_{2}(t)$ are assumed constant across the two consecutive symbol transmission periods and they can be defined as:

$$
\begin{aligned}
& \mathrm{h}_{1}(\mathrm{t})=\mathrm{h}_{1}(\mathrm{t}+\mathrm{T})=\mathrm{h}_{1}=\left|\mathrm{h}_{1}\right| \mathrm{e}^{\mathrm{j} \theta 1} \\
& \mathrm{~h}_{2}(\mathrm{t})=\mathrm{h}_{2}(\mathrm{t}+\mathrm{T})=\mathrm{h}_{2}=\left|\mathrm{h}_{2}\right| \mathrm{e}^{\mathrm{j} \theta 2}
\end{aligned}
$$


International Journal of Distributed and Parallel Systems (IJDPS) Vol.3, No.4, July 2012

The receiver receives $r_{1}$ and $r_{2}$ denoting the two received signals over the two consecutive symbol periods for time $\mathrm{t}$ and $\mathrm{t}+\mathrm{T}$. The received signals can be expressed by:

$$
\left[\begin{array}{l}
\mathrm{r}_{1} \\
\mathrm{r}_{2}
\end{array}\right]=\left[\begin{array}{cc}
\mathrm{s}_{1} & \mathrm{~s}_{2} \\
-\mathrm{s}_{2}{ }^{*} & \mathrm{~s}_{1}{ }^{*}
\end{array}\right]\left[\begin{array}{l}
\mathrm{h}_{1} \\
\mathrm{~h}_{2}
\end{array}\right]+\left[\begin{array}{l}
\mathrm{n}_{1} \\
\mathrm{n}_{2}
\end{array}\right]=\left[\begin{array}{c}
\mathrm{h}_{1} \mathrm{~s}_{1}+\mathrm{h}_{2} \mathrm{~s}_{2}+\mathrm{n}_{1} \\
-\mathrm{h}_{1} \mathrm{~s}_{2}{ }^{*}+\mathrm{h}_{2} \mathrm{~s}_{1}{ }^{*}+\mathrm{n}_{2}
\end{array}\right]
$$

The maximum likelihood (ML) decoder chooses a pair of signals $\left(\hat{\mathrm{s}}_{1}, \hat{\mathrm{s}}_{2}\right)$ from the signal constellation to minimize the distance metric over all possible values of $\hat{\mathrm{s}}_{1}$ and $\hat{\mathrm{s}}_{2}$.

$\mathrm{d}^{2}\left(\mathrm{r}_{1}, \mathrm{~h}_{1} \hat{\mathrm{s}}_{1}+\mathrm{h}_{2} \hat{\mathrm{s}}_{2}\right)+\mathrm{d}^{2}\left(\mathrm{r}_{2},-\mathrm{h}_{1} \hat{\mathrm{s}}_{2} *+\mathrm{h}_{2} \hat{\mathrm{s}}_{1} *\right)$

$=\left|\mathrm{r}_{1}-\mathrm{h}_{1} \hat{\mathrm{s}}_{1}-\mathrm{h}_{2} \hat{\mathrm{S}}_{2}\right|^{2}+\left|\mathrm{r}_{2}+\mathrm{h}_{1} \hat{\mathrm{S}}_{2} *-\mathrm{h}_{2} \hat{\mathrm{S}}_{1} *\right|^{2}$

For phase-shift keying (PSK) signals, the decision rule can be expressed by:

$\mathrm{d}^{2}\left(\hat{\mathrm{s}}_{1}, \mathrm{~s}_{\mathrm{i}}\right) \leq \mathrm{d}^{2}\left(\hat{\mathrm{s}}_{1}, \mathrm{~s}_{\mathrm{k}}\right) \vee \mathrm{i} \neq \mathrm{k}$

$\mathrm{d}^{2}\left(\hat{\mathrm{s}}_{2}, \mathrm{~s}_{\mathrm{i}}\right) \leq \mathrm{d}^{2}\left(\mathrm{~s} 2, \mathrm{~s}_{\mathrm{k}}\right) \vee \mathrm{i} \neq \mathrm{k}$

The combiner shown in Figure 3 builds the following two combined signals that are sent to the maximum likelihood detector.

$$
\left[\begin{array}{c}
\widetilde{\mathrm{s}}_{1} \\
\widetilde{\mathrm{s}}_{2}
\end{array}\right]=\left[\begin{array}{cc}
\mathrm{h}_{1}^{*} & \mathrm{~h}_{2} \\
\mathrm{~h}_{2}{ }^{*} & -\mathrm{h}_{1}
\end{array}\right]\left[\begin{array}{c}
\mathrm{r}_{1} \\
\mathrm{r}_{2}^{*}
\end{array}\right]=\left[\begin{array}{l}
\mathrm{h}_{1}{ }^{*} \mathrm{r}_{1}+\mathrm{h}_{2} \mathrm{r}_{2}{ }^{*} \\
\mathrm{~h}_{2}{ }^{*} \mathrm{r}_{1}-\mathrm{h}_{1} \mathrm{r}_{2}{ }^{*}
\end{array}\right]
$$

The encoder and decoder of the Alamouti scheme system is shown in Figure 2 and Figure 3. Here the information to be transmitted is modulated and fed to the space time encoder. The space time encoder consists of two transmit antennas as part of the multiple input multiple output technology [6]. So here the information is transmitted through two separate antennas. Each transmitting and the receiving antenna pair has a channel, represented by different channel coefficients. These channel coefficients play a major role in the design of the system. As the number of antennas increases at both the ends of the channel, the complexity of the system also increases.

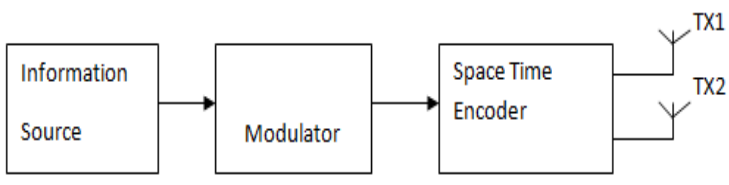

Figure 2: Alamouti space-time encoder

In the decoder, the received signal is fed to the channel estimator. The estimated coefficients of the channel together with the combiner are given as the input to the maximum likelihood detector. The detected signal is then fed to the demodulator. The demodulator gives the original information which is transmitted. 


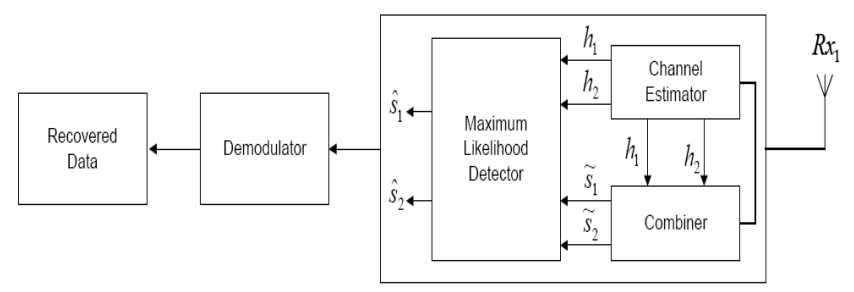

Figure 3: Alamouti space-time decoder

The space-time block codes are the higher version of the Alamouti scheme. i.e, increment of the number of antennas of the Alamouti scheme, the space-time block codes will result. As an example of the STBC's, a case of 4 transmitted antennas and one receive antenna is explained here.

\subsection{Four Transmit and One Receive Antenna}

At a given symbol period, four signals are transmitted simultaneously from four transmit antennas. The signal transmitted from antenna one $\left(\mathrm{Tx}_{1}\right)$ is denoted by $\mathrm{s}_{1}$, the signal from antenna two $\left(\mathrm{Tx}_{2}\right)$ by $\mathrm{s}_{2}$, the signal from antenna three $\left(\mathrm{Tx}_{3}\right)$ by $\mathrm{s}_{3}$ and the signal from antenna four $\left(\mathrm{Tx}_{4}\right)$ by $\mathrm{s}_{4}$. This process will go on in the same manner until transmitting the last row of the $\mathrm{G}_{4}$ transmission matrix as given in equation (11). This matrix has a rate of half $(1 / 2)$ and is used as STBC encoder to transmit any complex signal constellations. The encoding, mapping and transmission of the STBC can be summarized in Table 1.

Table 1: Encoding and mapping of STBC for four transmit antennas using complex signals

\begin{tabular}{|c|c|c|c|c|}
\hline & $\mathrm{Tx}_{1}$ & $\mathrm{Tx}_{2}$ & $\mathrm{Tx}_{3}$ & $\mathrm{Tx}_{4}$ \\
\hline $\mathrm{t}$ & $\mathrm{s}_{1}$ & $\mathrm{~s}_{2}$ & $\mathrm{~s}_{3}$ & $\mathrm{~s}_{4}$ \\
\hline $\mathrm{t}+\mathrm{T}$ & $-\mathrm{s}_{2}$ & $\mathrm{~s}_{1}$ & $-\mathrm{s}_{4}$ & $\mathrm{~s}_{3}$ \\
\hline $\mathrm{t}+2 \mathrm{~T}$ & $-\mathrm{s}_{3}$ & $\mathrm{~s}_{4}$ & $\mathrm{~s}_{1}$ & $-\mathrm{s}_{2}$ \\
\hline $\mathrm{t}+3 \mathrm{~T}$ & $-\mathrm{s}_{4}$ & $-\mathrm{s}_{3}$ & $\mathrm{~s}_{2}$ & $\mathrm{~s}_{1}$ \\
\hline $\mathrm{t}+4 \mathrm{~T}$ & $\mathrm{~s}_{1} *$ & $\mathrm{~s}_{2}{ }^{*}$ & $\mathrm{~s}_{3} *$ & $\mathrm{~s}_{4}{ }^{*}$ \\
\hline $\mathrm{t}+5 \mathrm{~T}$ & $-\mathrm{s}_{2} *$ & $\mathrm{~s}_{1} *$ & $-\mathrm{s}_{4} *$ & $\mathrm{~s}_{3} *$ \\
\hline $\mathrm{t}+6 \mathrm{~T}$ & $-\mathrm{s}_{3} *$ & $\mathrm{~s}_{4} *$ & $\mathrm{~s}_{1} *$ & $-\mathrm{s}_{2} *$ \\
\hline $\mathrm{t}+7 \mathrm{~T}$ & $-\mathrm{s}_{4} *$ & $-\mathrm{s}_{3}^{*}$ & $\mathrm{~s}_{2}^{*}$ & $\mathrm{~s}_{1} *$ \\
\hline
\end{tabular}

For the four transmit and one receive antenna system, the channel coefficients are modeled by a complex multiplicative distortions, $\mathrm{h}_{1}$ for the first transmit antenna, $\mathrm{h}_{2}$ for the second transmit antenna, $h_{3}$ for the third transmit antenna and $h_{4}$ for the fourth transmit antenna. The channel coefficients explained above are summarized in Table 2. 
Table 2: Four transmit and one receive antenna channel coefficients

\begin{tabular}{|c|c|}
\hline & $\mathrm{Rx}$ \\
\hline $\mathrm{Tx}_{1}$ & $\mathrm{~h}_{1}$ \\
\hline $\mathrm{Tx}_{2}$ & $\mathrm{~h}_{2}$ \\
\hline $\mathrm{Tx}_{3}$ & $\mathrm{~h}_{3}$ \\
\hline $\mathrm{Tx}_{4}$ & $\mathrm{~h}_{4}$ \\
\hline
\end{tabular}

Figure 4 shows the schematic diagram of the space-time block code with four transmit and one receive antenna system.

Assuming the fading is constant over the four consecutive symbols and then channel coefficients can be represented as

$$
\begin{aligned}
& \mathrm{h}_{1}(\mathrm{t})=\mathrm{h}_{1}(\mathrm{t}+\mathrm{T})=\mathrm{h}_{1}=\left|\mathrm{h}_{1}\right| \mathrm{e}^{\mathrm{j} \theta 1} \\
& \mathrm{~h}_{2}(\mathrm{t})=\mathrm{h}_{2}(\mathrm{t}+\mathrm{T})=\mathrm{h}_{2}=\left|\mathrm{h}_{2}\right| \mathrm{e}^{\mathrm{j} \theta 2} \\
& \mathrm{~h}_{3}(\mathrm{t})=\mathrm{h}_{3}(\mathrm{t}+\mathrm{T})=\mathrm{h}_{3}=\left|\mathrm{h}_{3}\right| \mathrm{e}^{\mathrm{j} \theta 3} \\
& \mathrm{~h}_{4}(\mathrm{t})=\mathrm{h}_{4}(\mathrm{t}+\mathrm{T})=\mathrm{h}_{4}=\left|\mathrm{h}_{4}\right| \mathrm{e}^{\mathrm{j} \theta 4}
\end{aligned}
$$

where $\left|\mathrm{h}_{\mathrm{i}}\right|$ and $\theta_{\mathrm{i}}, \mathrm{i}=1,2,3,4$ are the amplitude and phase shift for the path from transmit antenna $i$ to receive antenna $j$. The receiver in this case will receive eight different signals in eight different time slots. The received signals can be represented as

$$
\begin{aligned}
& \mathrm{r}_{1}=\mathrm{h}_{1} \mathrm{~s}_{1}+\mathrm{h}_{2} \mathrm{~s}_{2}+\mathrm{h}_{3} \mathrm{~s}_{3}+\mathrm{h}_{4} \mathrm{~s}_{4}+\mathrm{n}_{1} \\
& \mathrm{r}_{2}=-\mathrm{h}_{1} \mathrm{~s}_{2}+\mathrm{h}_{2} \mathrm{~s}_{1}-\mathrm{h}_{3} \mathrm{~s}_{4}+\mathrm{h}_{4} \mathrm{~s}_{3}+\mathrm{h}_{2} \\
& \mathrm{r}_{3}=-\mathrm{h}_{1} \mathrm{~s}_{3}+\mathrm{h}_{2} \mathrm{~s}_{4}+\mathrm{h}_{3} \mathrm{~s}_{1}-\mathrm{h}_{4} \mathrm{~s}_{2}+\mathrm{n}_{3} \\
& \mathrm{r}_{4}=-\mathrm{h}_{1} \mathrm{~s}_{4}-\mathrm{h}_{2} \mathrm{~s}_{3}+\mathrm{h}_{3} \mathrm{~s}_{2}+\mathrm{h}_{4} \mathrm{~s}_{1}+\mathrm{h}_{4} \\
& \mathrm{r}_{5}=\mathrm{h}_{1} \mathrm{~s}_{1} *+\mathrm{h}_{2} \mathrm{~s}_{2}^{*}+\mathrm{h}_{3} \mathrm{~s}_{3}^{*}+\mathrm{h}_{4} \mathrm{~s}_{4}^{*}+\mathrm{n}_{5} \\
& \mathrm{r}_{6}=-\mathrm{h}_{1} \mathrm{~s}_{2}^{*}+\mathrm{h}_{2} \mathrm{~s}_{1} *-\mathrm{h}_{3} \mathrm{~s}_{4}^{*}+\mathrm{h}_{4} \mathrm{~s}_{3}^{*}+\mathrm{n}_{6} \\
& \mathrm{r}_{7}=-\mathrm{h}_{1} \mathrm{~s}_{3}^{*}+\mathrm{h}_{2} \mathrm{~s}_{4} * \mathrm{~h}_{3} \mathrm{~s}_{1}^{*}-\mathrm{h}_{4} \mathrm{~s}_{2}^{*}+\mathrm{n}_{7} \\
& \mathrm{r}_{8}=-\mathrm{h}_{1} \mathrm{~s}_{4} *-\mathrm{h}_{2} \mathrm{~s}_{3} *+\mathrm{h}_{3} \mathrm{~s}_{2}^{*}+\mathrm{h}_{4} \mathrm{~s}_{1}^{*}+\mathrm{n}_{8}
\end{aligned}
$$


International Journal of Distributed and Parallel Systems (IJDPS) Vol.3, No.4, July 2012

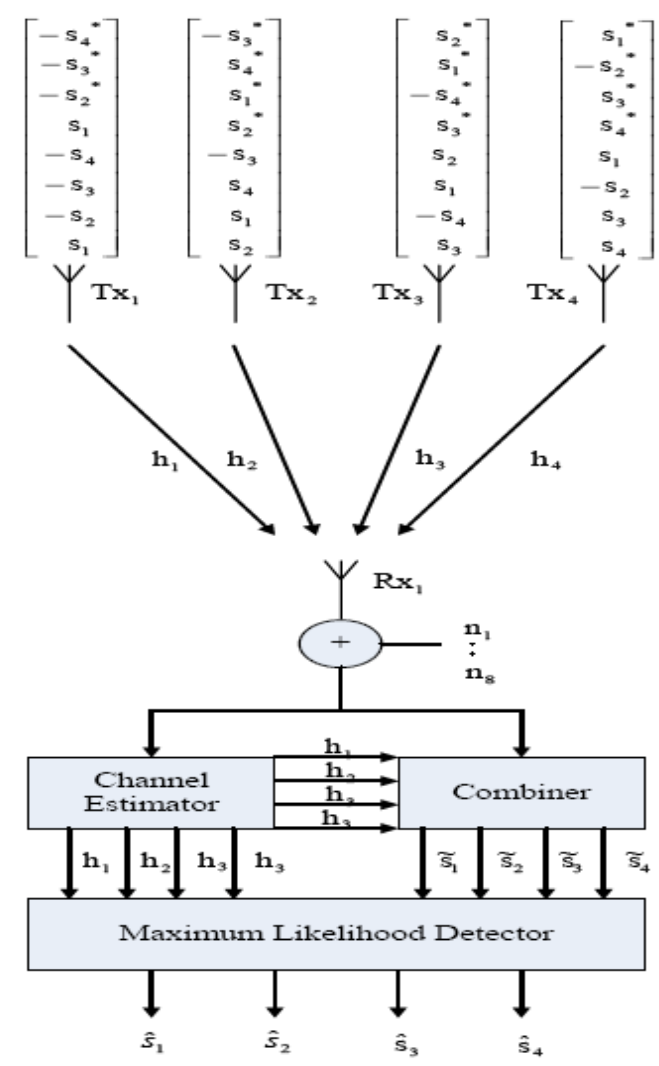

Figure 4: Space-time block code scheme with four transmit and one receive antennas

The combiner in Figure 4 builds the following four combined signals

$$
\begin{aligned}
& \tilde{\mathrm{s}}_{1}=\mathrm{h}_{1} * \mathrm{r}_{1}+\mathrm{h}_{2} * \mathrm{r}_{2}+\mathrm{h}_{3} * \mathrm{r}_{3}+\mathrm{h}_{4} * \mathrm{r}_{4}+\mathrm{h}_{1} \mathrm{r}_{5} *+\mathrm{h}_{2} \mathrm{r}_{6} * \mathrm{~h}_{3} \mathrm{r}_{7} *+\mathrm{h}_{4} \mathrm{r}_{8} * \\
& \tilde{\mathrm{s}}_{2}=\mathrm{h}_{2} * \mathrm{r}_{1}-\mathrm{h}_{1} * \mathrm{r}_{2}-\mathrm{h}_{4} * \mathrm{r}_{3}+\mathrm{h}_{3} * \mathrm{r}_{4}+\mathrm{h}_{2} \mathrm{r}_{5} *-\mathrm{h}_{1} \mathrm{r}_{6} *-\mathrm{h}_{4} \mathrm{r}_{7} *+\mathrm{h}_{3} \mathrm{r}_{8} * \\
& \tilde{\mathrm{s}}_{3}=\mathrm{h}_{3} * \mathrm{r}_{1}+\mathrm{h}_{4} * \mathrm{r}_{2}-\mathrm{h}_{1} * \mathrm{r}_{3}-\mathrm{h}_{2} * \mathrm{r}_{4}+\mathrm{h}_{3} \mathrm{r}_{5} * \mathrm{~h}_{4} \mathrm{r}_{6} *-\mathrm{h}_{1} \mathrm{r}_{7} *-\mathrm{h}_{2} \mathrm{r}_{8} * \\
& \tilde{\mathrm{s}}_{4}=-\mathrm{h}_{4} * \mathrm{r}_{1}-\mathrm{h}_{3} * \mathrm{r}_{2}+\mathrm{h}_{2} * \mathrm{r}_{3}-\mathrm{h}_{1} * \mathrm{r}_{4}-\mathrm{h}_{4} \mathrm{r}_{5} * \mathrm{~h}_{3} \mathrm{r}_{6} * \mathrm{~h}_{2} \mathrm{r}_{7} *-\mathrm{h}_{1} \mathrm{r}_{8} *
\end{aligned}
$$

These four combined signals are then sent to the maximum likelihood detector.

\subsection{Space-Time Block Codes for $\mathrm{N}_{\mathrm{t}}=4$}

For the case of 4 transmit antennas, with different code rates $1 / 2$ and $3 / 4$, the encoder matrix is given by $\mathrm{G}_{4}$ and $\mathrm{H}_{4}$. Both of them have the full diversity $4 \mathrm{~N}_{\mathrm{r}}$. The encoded matrices are given by: 
International Journal of Distributed and Parallel Systems (IJDPS) Vol.3, No.4, July 2012

$$
\mathcal{G}_{4}=\left(\begin{array}{rrrr}
s_{1} & s_{2} & s_{3} & s_{4} \\
-s_{2} & s_{1} & -s_{4} & s_{3} \\
-s_{3} & s_{4} & s_{1} & -s_{2} \\
-s_{4} & -s_{3} & s_{2} & s_{1} \\
s_{1}^{*} & s_{2}^{*} & s_{3}^{*} & s_{4}^{*} \\
-s_{2}^{*} & s_{1}^{*} & -s_{4}^{*} & s_{3}^{*} \\
-s_{3}^{*} & s_{4}^{*} & s_{1}^{*} & -s_{2}^{*} \\
-s_{4}^{*} & -s_{3}^{*} & s_{2}^{*} & s_{1}^{*}
\end{array}\right)
$$

$$
H_{4}=\left(\begin{array}{rrcc}
s_{1} & s_{2} & \frac{s_{3}}{\sqrt{2}} & \frac{s_{3}}{\sqrt{2}} \\
-s_{2}^{*} & s_{1}^{*} & \frac{s_{3}}{\sqrt{2}} & -\frac{s_{3}}{\sqrt{2}} \\
\frac{s_{3}^{*}}{\sqrt{2}} & \frac{s_{3}^{*}}{\sqrt{2}} & \frac{-s_{1}-s_{1}^{*}+s_{2}-s_{2}^{*}}{2} & \frac{-s_{2}-s_{2}^{*}+s_{1}-s_{1}^{*}}{2} \\
\frac{s_{3}^{*}}{\sqrt{2}} & -\frac{s_{3}^{*}}{\sqrt{2}} & \frac{s_{2}+s_{2}^{*}+s_{1}-s_{1}^{*}}{2} & -\frac{s_{1}+s_{1}^{*}+s_{2}-s_{2}^{*}}{2}
\end{array}\right)
$$

\section{Results and Discussion}

Alamouti space-time code is an orthogonal scheme that can achieve the full transmit diversity of $\mathrm{Nt}=2$. The bit-error-rate $(\mathrm{BER})$ versus signal-to-noise-ratio $(\mathrm{Eb} / \mathrm{No}(\mathrm{dB}))$ performance for Alamouti transmit diversity scheme on slow fading channels is evaluated by simulation. In the simulation, it is assumed that the receiver has the perfect knowledge of the channel coefficient. It is also assumed that the fading is mutually independent from each transmit antenna to each receive antenna and the total transmit power is the same for all cases.

Figure 5 shows the Alamouti scheme BER versus Eb/No performance with coherent BPSK modulation. From the simulation result, it is very clear to see that Alamouti scheme has the same diversity as the two-branch maximal ratio combining (MRC). However, from Figure 5, we can see that Almouti scheme performance is worse than the two-branch MRC by $3 \mathrm{~dB}$ and that is because the energy radiated from the single antenna in the MRC is the double of what radiates from each transmit antenna in the Alamouti scheme. To reach the same results, the total transmit power from each transmit antenna in the Alamouti scheme has to be equal to the transmit power of the MRC. Also Figure 6 gives the BER curves for the Alamouti scheme for QPSK and QAM modulations in Rayleigh channel [8].

It is possible to create different matrices which obey the orthogonality property. Here the simulation matrices defined are designated by $\mathrm{G}_{4}$ and $\mathrm{H}_{4}$ for different rates as $1 / 2$ and $3 / 4$ respectively. The Bit-Error Rate (BER) of orthogonal STBC for4 number of transmit antennas and a variation of different receiver antennas $(\mathrm{Nr}=1$ to 4$)$ through the Rayleigh fading channel is plotted here. The scheme is compared with different modulation schemes such as QPSK, 16QAM and 64-QAM. From Figures 7 to 10, we can infer that the performance of STBC using QPSK modulation is better than the result obtained by 16-QAM and 64-QAM regardless of the rate of transmission. This better performance is due to the number of bits that each modulated symbol can take. 
As the figure progresses from Figure 7 to 10, the BER curves approaches the ideal case. That is, other than the modulation technique, better results are produced by the system which uses more number of receiver antennas. This is due to the fact that as the number of receiver antennas increases, the diversity of the system will increase. Higher diversity will give better performance. So while designing the STBC for a particular application, it is needed to select the number of antennas at both ends of the communication link, the modulation and the rate of transmission. By using the proper STBC technology, it is possible to improve the data rate and range of the wireless communication systems. The complete simulation work has been done in MATLAB.

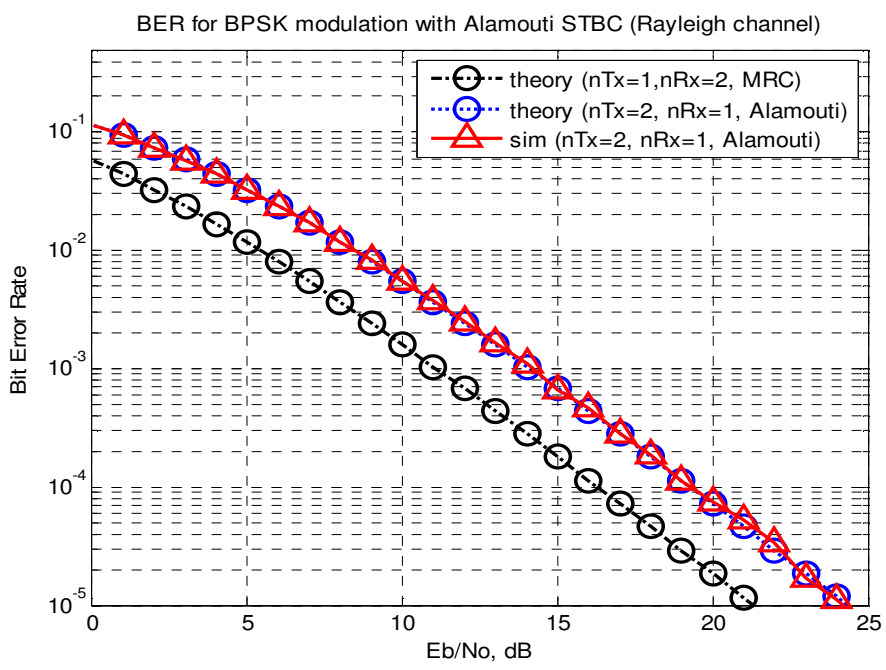

Figure 5: Performance of Alamouti scheme

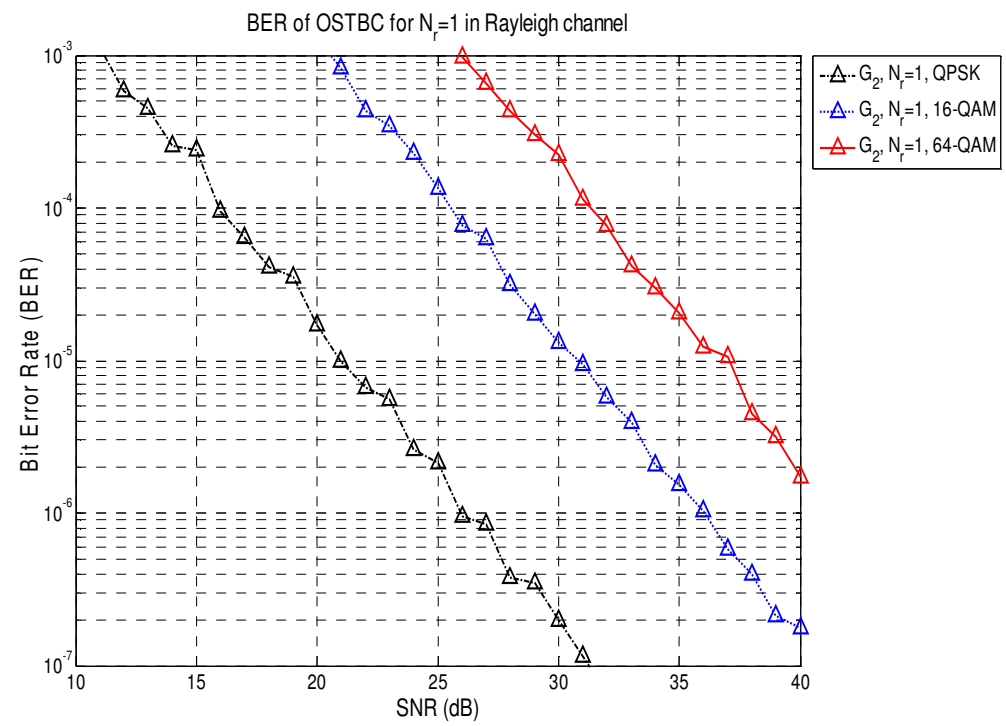

Figure 6: BER of Alamouti for QPSK, 16-QAM, 64-QAM in Rayleigh channel 
International Journal of Distributed and Parallel Systems (IJDPS) Vol.3, No.4, July 2012

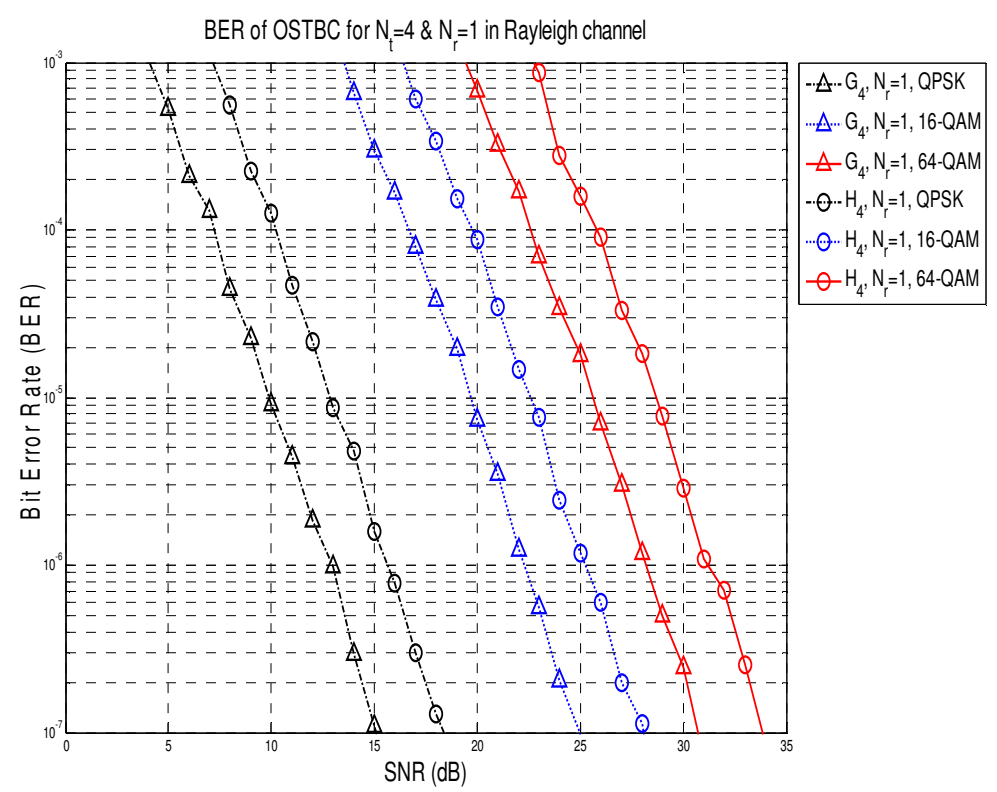

Figure 7: BER of OSTBC for $\mathrm{Nt}=4 \& \mathrm{Nr}=1$ in Rayleigh channel

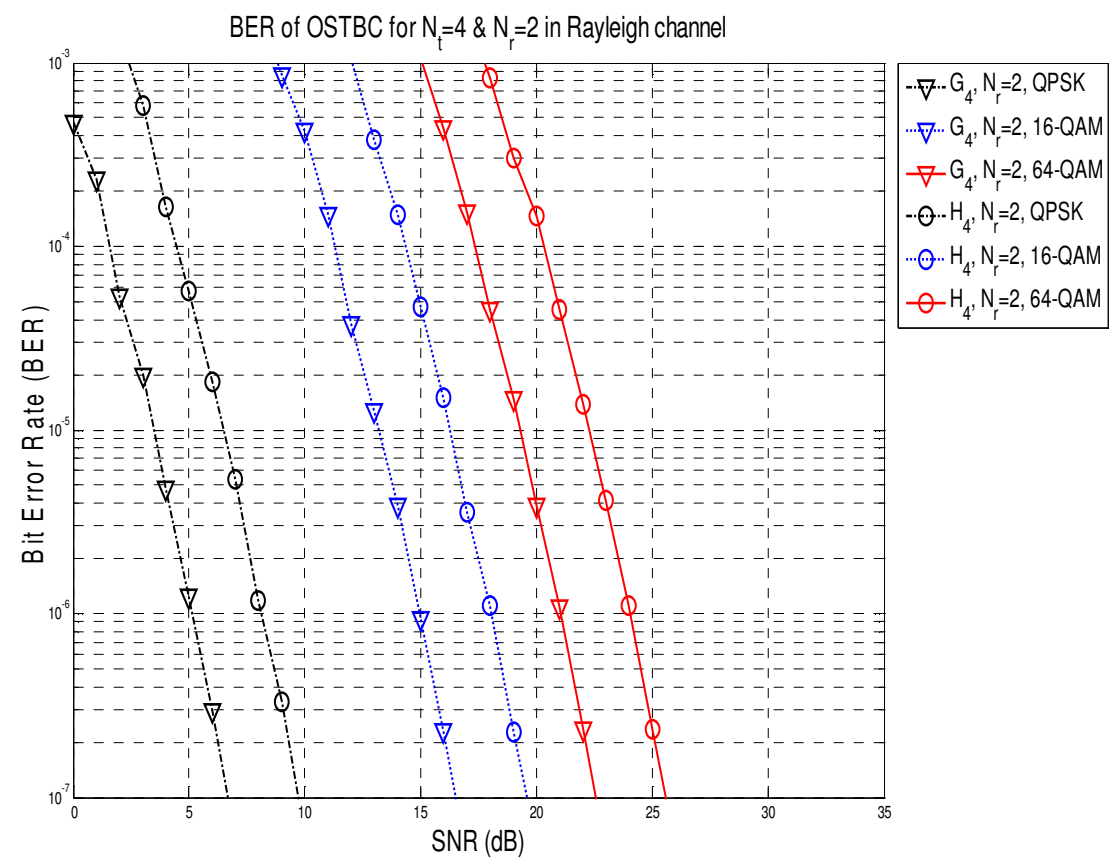

Figure 8: BER of OSTBC for $\mathrm{Nt}=4$ \& $\mathrm{Nr}=2$ in Rayleigh channel 
International Journal of Distributed and Parallel Systems (IJDPS) Vol.3, No.4, July 2012

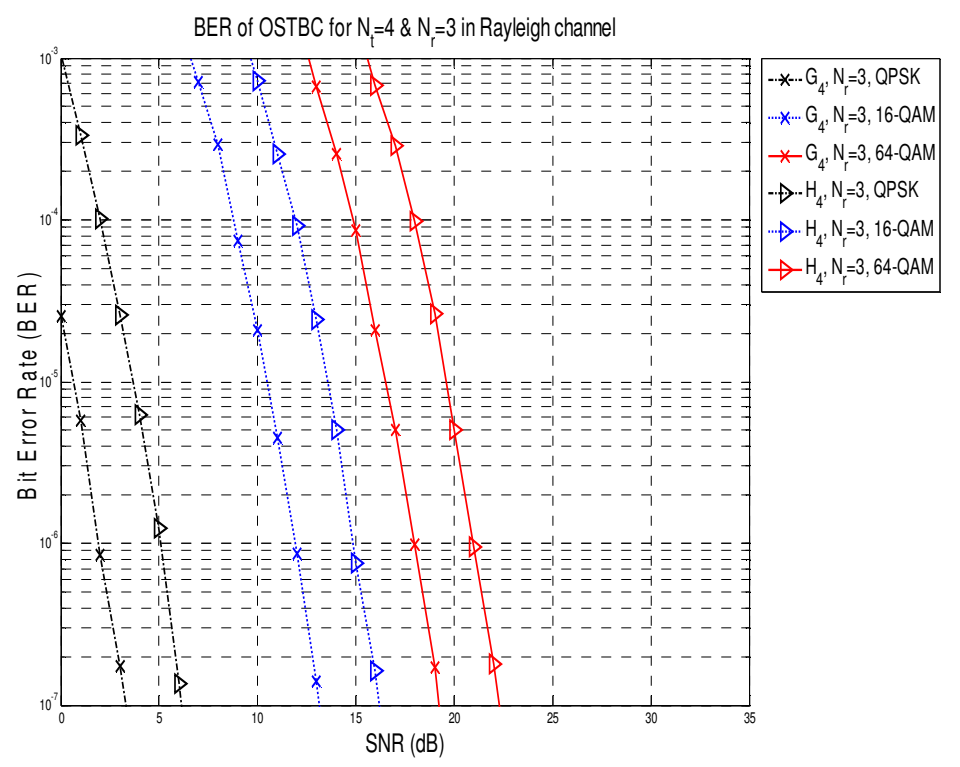

Figure 9: $\mathrm{BER}$ of $\mathrm{OSTBC}$ for $\mathrm{Nt}=4 \& \mathrm{Nr}=3$ in Rayleigh channel

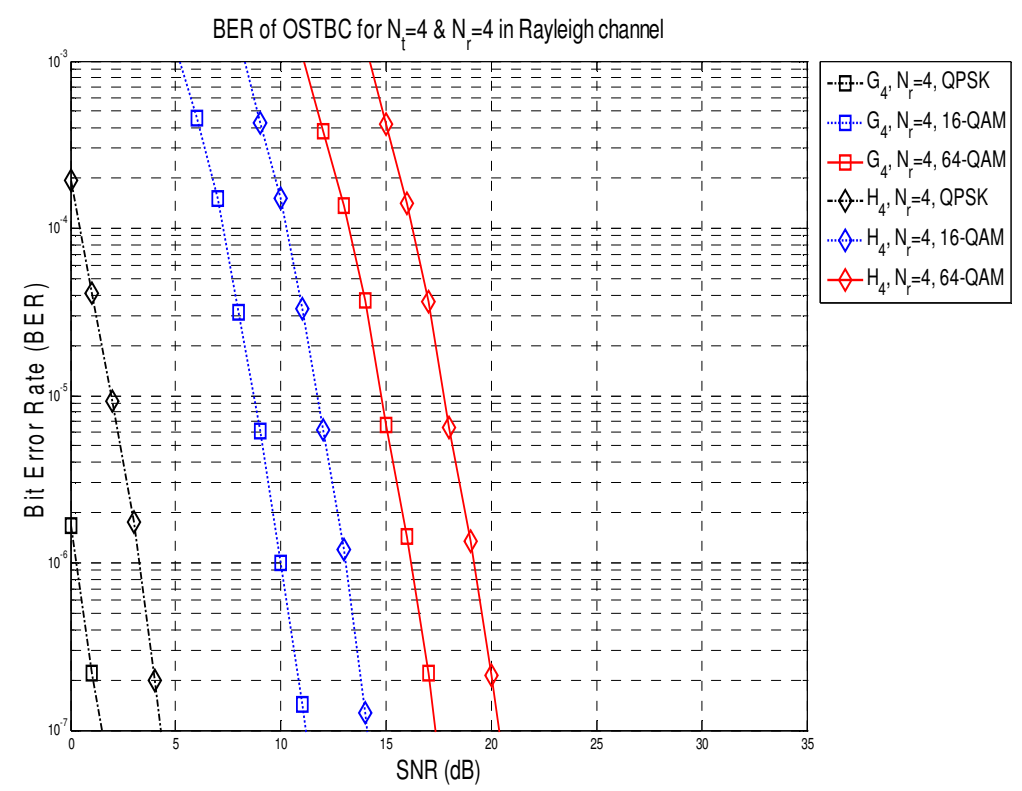

Figure 10: $\mathrm{BER}$ of OSTBC for $\mathrm{Nt}=4 \& \mathrm{Nr}=4$ in Rayleigh channel

\section{Conclusion and Future work}

This paper gives a basic overview of the MIMO technology. A basic introduction to Space-Time Coding has been provided by presenting Alamouti's scheme. The Alamouti scheme has been simulated for BPSK modualation in Rayleigh channel. The same Alamouti scheme has been again simulated in Rayleigh channel for QPSK, 16-QAM and 64-QAM modulations and the BER are compared. After that the BER of Orthogonal Space-Time Block Coding that has 4 
International Journal of Distributed and Parallel Systems (IJDPS) Vol.3, No.4, July 2012

number of transmit antennas has been determined for different code rates and modulation (QPSK, 16-QAM, 64-QAM). The better BER curve produced by a system which uses more number of antennas at both sides of the communication link. A particular application decides which modulation can be used. For example, in technologies like TV satellite transmission, higher modulation methods (256-QAM and 512-QAM) could be employed because the accuracy of received data at the user end is not essential. Other correction techniques could be employed to improve the performance of such systems. However, in mobile technology, the biterror-rate is very important. In this case, accuracy is essential. Therefore, lower order modulation methods (QPSK and 16-QAM) are usually employed. So the application decides which modulation and the combination of antennas in the communication link.

Finally as a future expansion of this paper, it is possible to introduce different modulation schemes to increase the data rates. Also we can increase the number of antennas at both transmitter and receiver without introducing any interference in between the antennas.

\section{REFERENCES}

1. Daniel W. Bliss, Keith W. Forsythe, and Amanda M. C "MIMO Wireless Communication “, Lincoln Laboratory Journal, Vol.15, No.1, 2005.

2. V. Tarokh, N. Seshadri, and A. Calderbank, "Space-time block codes from orthogonal designs", IEEE Trans. Information Theory, vol. 45, pp. 1456-1467, July 1999.

3. S. Alamouti, "A simple transmit diversity technique for wireless communications", IEEE Journal on Selected Areas in Communications, vol. 16, pp. 1451-1458, Oct 1998.

4. C. Fragouli, N. Al-Dhahir, and W. Turin, "Training-based Channel Estimation for Multiple-antenna Broadband Transmissions", IEEE Transactions on Wireless Communications, Vol. 2, No. 2, March 2003.

5. Marcelo M. Carvalho \& J. J. Garcia-Luna-Aceves.," Analytical modelling of ad-hoc networks that utilize space time coding", 4th International Symposium on AdHoc and Wireless Networks, IEEE, 2006

6. David Gesbert, Mansoor Shafi, Da-shan Shiu, Peter J. Smith, and Ayman Naguib, "From Theory to Practice: An Overview of MIMO Space-Time Coded Wireless Systems", IEEE journal on selected areas in communications, vol. 21, no. 3, April 2003

7. V. Tarokh, N. Seshadri, and A. Calderbank, "Space-time codes for high data rate wireless communications: Performance criterion and code construction", IEEE Trans. Information Theory, vol. 44, pp. 744-765, Mar 1998

8. B. M. Hochwald and T. L. Marzetta, "Unitary Space-time Modulation for Multiple Antenna Communications in Rayleigh Flat Fading," IEEE Transactions on Information Theory, Vol. 46, No. 2, pp. 543-564, March 2000.

9. Andrea Goldsmith, “Wireless Communications”, Stanford University, Cambridge University Press, 2005.

10. Marcelo M. Carvalho \& J. J. Garcia-Luna-Aceves, "Modeling Wireless AdHoc Networks with Directional Antennas”, IEEE Trans. Information Theory, vol. 47, pp. 846-868, Mar 2000.

11. Ming $\mathrm{Hu}$ and Junshan Zhang, "MIMO Ad Hoc Networks: Medium Access Control, Saturation Throughput and Optimal Hop Distance”, IEEE Trans. Information Theory, vol. 34, pp. 367-380, Mar 2004

12. Gerald W. Recktenwald "Numerical Methods with Matlab: Implementations and Applications", Prentice-Hall, 2001.

13. J. Wu and Gary J. Saulnier, "Orthogonal Space-time Block Code Over Time-varying Flat-fading Channels: Channel Estimation, Detection, and Performance Analysis", IEEE Transactions on Communications, Vol. 55, no. 5, May 2007. 
International Journal of Distributed and Parallel Systems (IJDPS) Vol.3, No.4, July 2012

14. G. J. Foschini and M. J. Gans, "On Limits of Wireless Communications in a Fading Environment When using Multiple Antennas”, Wireless Personal Communications, Vol. 6, pp. 311-335, 1998.

15. A. Molisch, "Wireless Communications”, Wiley-IEEE Press, 2005.

\section{Authors:}

Mr. Santumon.S.D: He has completed B.Tech from Government College of Engineering, Kannur, Kerala in 2004 and M.Tech in Digital Electronics and Communication Systems From Malnad College of Engineering Hassan Karnataka in 2012. He has about 10 months experience in an industry and 5 years of experience in teaching. Currently he is working as an Assiastant Professor in an engineering College.

Mrs. B.R. Sujatha: She is doing her Ph.D in Visvesvaraya Technological University under the guidance of Dr. P V Sathyanarayana,Principal , Malnad Colege of Engineering in wireless networks. She has about 20 years of teaching experience. 